\title{
Technique of Biogas-HHO Gas Supply for SI Engine
}

\author{
Bui Van Ga, Bui Thi Minh Tu, Truong Le Bich Tram, Bui Van Hung \\ Danang University of Science and Technology-The University of Danang \\ 54, Nguyen Luong Bang Street, Danang, Vietnam
}

\begin{abstract}
The paper presents a new technique to control the airfuel ratio of a SI engine fueled with biogas-HHO gas based on the simulation of pressure variation in the intake manifold. With a fi-correction valve integrated into the conventional gaseous fuel supplying valve, the equivalence ratio of the mixture can be controlled in a narrow gap around the stoichiometric value. The fi-correction valve is in action under the effect of vacuum which decreases as decreasing of engine speed or/and increasing of flow obturation. Without fi-correction valve, the equivalence ratio of biogas-HHO gas fueling engine decreases significantly as increasing of engine speed. In this case, with the same gas supply condition, the suitable mixture for low engine speed becomes too poor at high engine speed; conversely, optimal mixture for high engine speed becomes too rich at low engine speed. The compact gaseous fuel supplying kit included a mixer, a main fuel injection valve and a fi-correction valve can provide a stable equivalence ratio at any engine speed regimes. This new concept of air-fuel ratio control can overcome the inconveniences of the conventional system and it has demonstrated as an appropriate technique for biogas-HHO gas supplying to SI engine in practice.
\end{abstract}

Keywords: Renewable Fuels; Biogas; HHO Gas; Biogas Engines; Air to Fuel Ratio

SI Spark ignition

NOMENCLATURE

${ }^{\circ} \mathrm{CA}$

Degree crankshaft angle

p Pressure (bar)

n $\quad$ Engine speed (rpm)

$\mathrm{v} \quad$ Fluid velocity $(\mathrm{m} / \mathrm{s})$

$\mathrm{MxCy} \quad$ Biogas constituted by $10 \mathrm{x} \% \mathrm{CH}_{4}$ and $10 \mathrm{y} \% \mathrm{CO}_{2}$ by volume

$\begin{array}{ll}\phi & \text { Equivalence ratio } \\ \varphi & \text { Crankshaft angle } \\ \alpha & \text { Rotation angle of butterfly valve in range } \\ & \text { of } 0^{\circ} \text { and } 60^{\circ}\end{array}$

\section{INTRODUCTION}

The main target of controlling the air-fuel ratio is to maintain the equivalence ratio of the mixture close to the stoichiometric value. Under this condition, the engine produces the highest performance and the lowest pollution emissions. In the other hand, the maintenance of stoichiometric mixture is important to ensure the efficient operation of the catalytic treatment system. In fact, it is very difficult to maintain this ratio due to the frequent change of engine operation mode [1].

There are several technologies to control air-fuel ratio for gaseous fuels. But these technologies are often applied to traditional fuels, high calorific value, such as LPG, CNG. Renewable gaseous fuels or gas fuel recovered from waste processing often contain impurities, thus, their calorific value is generally low. The common technique of supplying these gases into the engine is to use the venturi throat. To maintain stability of the engine, a relatively rich mixture must be supplied. Normally, the equivalence ratio of the engine is in range of 1.2-1.3 [2]. The conventional technology often used the diaphragm vacuum-type fuel valves for gaseous fuel supply to the SI engine [3]. With this technology, we must accept a wide range of variation of the equivalence ratio. To improve the characteristic of gas fuel supply to the engine, an additional fuel supply valve with mechanism control was proposed [4].

On the new generation engine, the air-fuel ratio is adjusted by the electronic control system with an oxygen sensor mounted on the exhaust manifold or a by the technique of measurement of gas flow injected into the cylinder [1]. These techniques have demonstrated an efficient way to control the air-fuel ratio within the narrow range around the stoichiometric value [5]. With the development of intelligent systems, many new models for controlling of equivalence ratio have been proposed such as adaptive controllers [6], observer-based controllers [7], Model Predictive Controllers [8-9]. The use of electronic intake throat is also considered an existing solution for air-fuel ratio control [10].

The research on air-fuel ratio control in the literature is mostly focused on the traditional fuels. It seems to be rare publication on poor renewable fuels such as biogas which is one of the most popular renewable gas fuels in the development countries, particularly in tropical region. Using biogas as a fuel for internal combustion engines is an effective solution to save fossil fuels and to reduce the green house gas emission [11]. Biogas can be used on site of production for power generation or on vehicles [12]. Raw biogas contains high $\mathrm{CO}_{2}$ content which results in a reduction of the calorific value and flame speed. To improve the quality of the combustion process, the enrichment of biogas by hydrogen has been proposed by many authors [13-14].

One of the important tasks of the conversion of traditional engine to biogas engine is to design and manufacture an appropriate gaseous fuel supplying system. Due to various types and sizes of traditional engines used in rural area, simulation calculations to determine the basic structure and size of the mixer throat have been published [15-20]. In these works, gaseous fuel supply is conducted by a mechanical valve which is controlled by the speed governor or by accelerating mechanism. Biogas flow depends on opening 
level of the valve. Due to the limit range of valve movement, it is very difficult to adjust the fuel flow with accuracy. This means that with the mechanical fuel supplying valve, a large range of variation of equivalence must be accepted. This can be applied in case of stationary power production engine which rarely changes operation regime [21].

To improve the efficiency of gaseous fuel supplying to SI engine, a concept of three-functional valve has been suggested [4]. This concept can be applied successfully with rich gaseous fuel such as LPG. In this case a minimum change in gas flow results in a considerable change in engine output power. For poor gaseous fuel such as biogas, the control air-fuel ratio is more complicated. In this case, to adjust output power of the engine, a considerable quantity of fuel must be injected. More fuel injected in a limit of time, particularly with high engine speed, is really a challenge of air-fuel ratio control of the engine fueled with poor gaseous fuel.

In this study, we propose a new concept of air-fuel ratio control for SI engine fueled with biogas enriched by HHO gas. This engine is the main component of the hybrid renewable power production biogas-solar. HHO gas is produced by solar power and supplied directly to the engine via the mixer. The addition of HHO gas to biogas is an effective way to improve the combustion quality, thus, enhances the performance and reduces harmful emission of the engine [22].

\section{SIMULATION OF BIOGAS-HHO GAS FUEL SUPPLY PROCESS}

The simulation of biogas-HHO gas fuel supply process is conducted by FLUENT software on the Samdi S3600B-1 SI engine with $68 \mathrm{~mm}$ of cylinder diameter and $56 \mathrm{~mm}$ of piston stroke. The engine compression ratio is 8.5 and the rate speed is $3000 \mathrm{rpm}$. The intake system is modified to provide biogas-HHO gas with throat venturi, biogas nozzle, HHO supply tube as described in Fig. 1. In the following section, the static pressure is averaged on sections S1, S2, S3, S4 and S5.

The calculation starts at the beginning of intake process and stops at the end of compression process. The butterfly valve rotates around its axe from $0^{\circ}$ (full opening) to $60^{\circ}$ (complete closing). The turbulence phenomenon is simulated by the standard $\mathrm{k}-\varepsilon$ model. Boundary conditions include pressure, temperature, and gas mixture compositions at air intake surface, biogas intake surface, HHO intake surface.

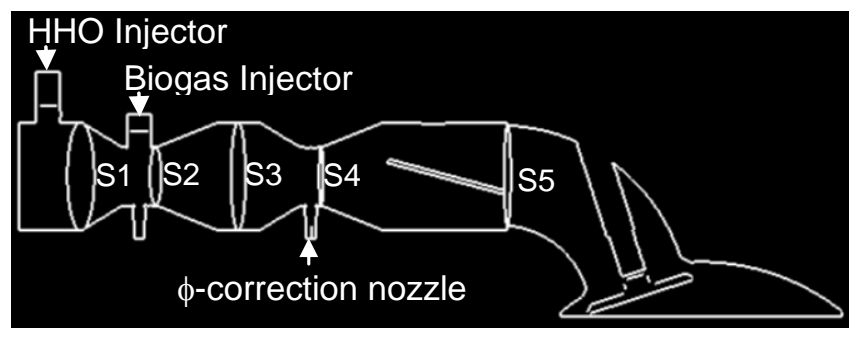

Fig. 1: Retrofit intake manifold of the Samdi S3600B-1 engine for biogasHHO fuel supply

In the simulation, biogas is denoted by $\mathrm{MxCy}$ where $10 \mathrm{x}$ is mole fraction of $\mathrm{CH}_{4}(\%)$ and $10 \mathrm{y}$ is mole fraction of $\mathrm{CO}_{2}$
(\%). HHO gas contains $1 / 3 \mathrm{O}_{2}$ and $2 / 3 \mathrm{H}_{2}$ by volume. The input pressure of biogas is $4 \mathrm{kPa}$ and the input of $\mathrm{HHO}$ gas is $3 \mathrm{kPa}$. Temperature of the fuels is $310 \mathrm{~K}$.

\section{RESULTS AND DISCUSSION}

\section{A. Pressure variation in the intake manifold}

Fig. 2 shows the contours of velocity and static pressure on the longitudinal section of the engine at $90^{\circ} \mathrm{CA}$ at engine speed of $1500 \mathrm{rpm}$ and $3500 \mathrm{rpm}$, no fuel supply. It can be observed that the highest average air velocity is found at the throat where the vacuum reaches the maximum value. The velocity distribution as well as the pressure in the intake manifold are almost the same when the engine speed changes. However, the value of velocity and vacuum increased sharply when engine speed increases. As shown in Fig. 2, the maximum air velocity is $120 \mathrm{~m} / \mathrm{s}$ as engine speed of 1500 $\mathrm{rpm}$, but it increases to $200 \mathrm{~m} / \mathrm{s}$ as engine speed of $3000 \mathrm{rpm}$. The maximum vacuum is $10 \mathrm{kPa}$ in the first case and $40 \mathrm{kPa}$ in the second case.

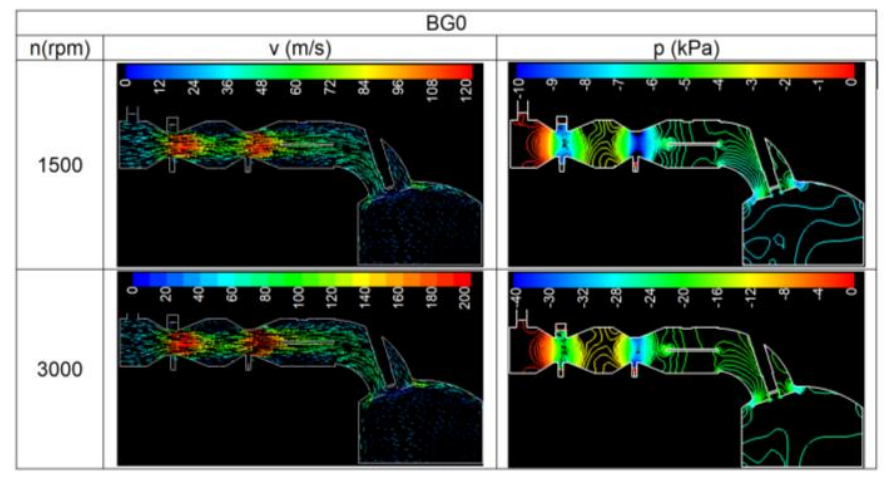

Fig. 2: The contour of velocity and static pressure on the longitudinal section as engine operates at speed of $1500 \mathrm{rpm}$ and $3000 \mathrm{rpm}$ (without fuel supply)
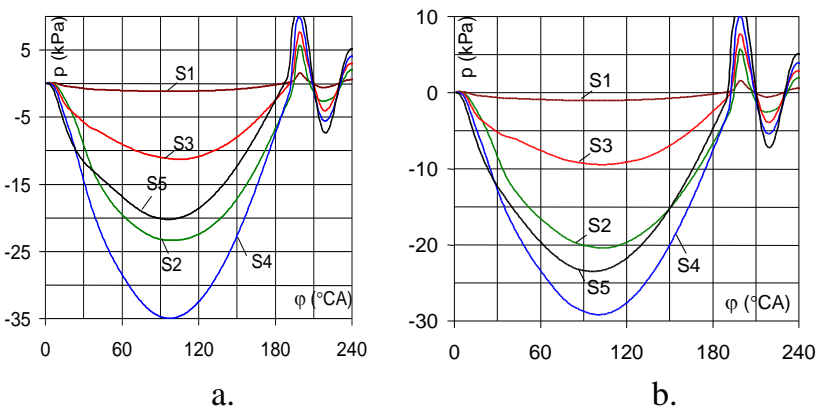

Fig. 3: Variation of static pressure on the cross sections S1, S2, S3, S4 and S5 according to crankshaft rotation angle as the throttle valve position $\alpha=0^{\circ}$ (a) and $\alpha=30^{\circ}$ (b) (n=3000 rpm, without fuel supply)

Fig. 3a and Fig.3b present the variation of average static pressure on the cross sections $\mathrm{S} 1, \mathrm{~S} 2, \mathrm{~S} 3, \mathrm{~S} 4$ and S5 in case of butterfly valve angle $\alpha=0^{\circ}$ and $\alpha=30^{\circ}$. The engine operates at speed of $3000 \mathrm{rpm}$ without fuel injection. It can be seen that the highest vacuum is observed at the section S4 of the second venturi. The vacuum at the throat of the first venturi is about $10 \mathrm{kPa}$ lower than that of the second venturi. The vacuum in the downstream of the butterfly valve increases gradually as $\alpha$ increases. At full opening of butterfly valve, the vacuum at the section $\mathrm{S} 2$ is higher than that of the section 
S5. But at $\alpha=30^{\circ}$, the vacuum at the section S5 becomes higher than that at $\mathrm{S} 2$.

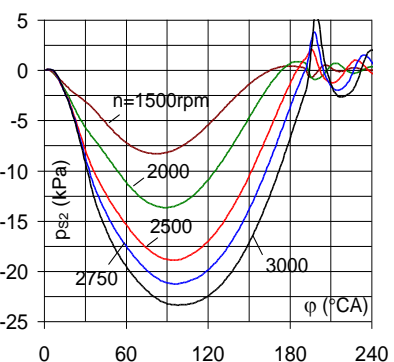

$a$.

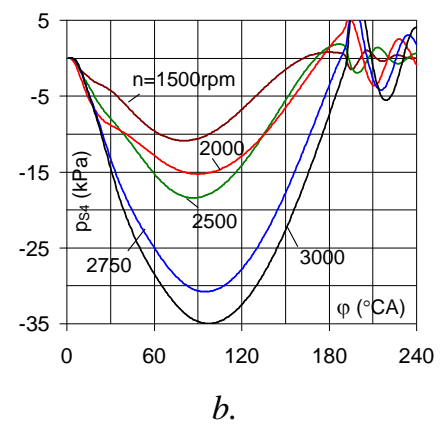

$b$.
Fig. 4: Effects of engine speed on variation of static pressure on cross section S2 (a) and S4 (b) according to crankshaft rotation angle $\left(\alpha=0^{\circ}\right.$, without fuel supply)

Fig. $4 \mathrm{a}$ and Fig. $4 \mathrm{~b}$ illustrate the effect of engine speed on the variation of static pressure at the cross section S2 and S4 when the butterfly valve is fully opened. The vacuum pressure in the intake manifold respects to Bernoulli's law. Due to the increase of air velocity as increasing of engine speed, the vacuum at a given section increases sharply with $\mathrm{n}$. At the cross section $\mathrm{S} 2$, the maximum vacuum is only about 8 $\mathrm{kPa}$ when the engine speed is $1500 \mathrm{rpm}$, but it reaches over $23 \mathrm{kPa}$ when the engine speed is $3000 \mathrm{rpm}$. Similarly, maximum vacuum at the cross section $\mathrm{S} 4$ increases from 8 $\mathrm{kPa}$ to $35 \mathrm{kPa}$ as the engine speed increases from $1500 \mathrm{rpm}$ to $3000 \mathrm{rpm}$. The peak of vacuum curve gradually moves towards the end of the intake process when the engine speed increases. This can be explained by the inertia of the air stream. When the engine speed increases, the higher inertia of the air flow leads to the vacuum continues to increase as the piston speed has begun to decrease.

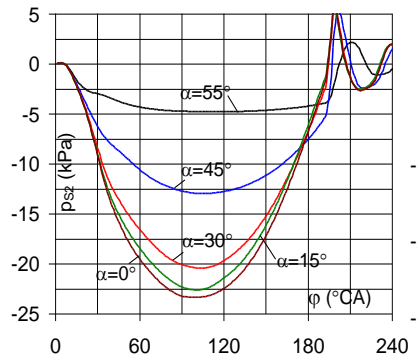

$a$.

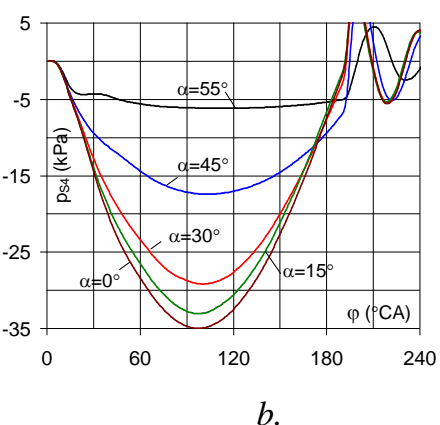

b.
Fig. 5: Effects of throttle valve position on variation of static pressure on cross section $\mathrm{S} 2$ (a) and $\mathrm{S} 4$ (b) (n=3000 rpm, without fuel supply)

At a given engine speed, the vacuum in intake manifold decreases as the engine is throttled down. Effects of the butterfly valve position on the vacuum at the sections S2 and $\mathrm{S} 4$ are shown in Fig.5a and Fig. 5b. The maximum vacuum at these sections slightly changed as $\alpha<30^{\circ}$, but when the flow section is strongly throttled it varied sharply. This is due to the flow section is more sensible as the butterfly valve tightly closes. The tendency of variation of vacuum pressure on the section $\mathrm{S} 2$ or section $\mathrm{S} 4$ is not quite different but the absolute value of vacuum at the section S4 is about $40 \%$ higher than that at the section $\mathrm{S} 2$.
The above results show that the vacuum at venturi decreases as throttling of flow section and/or as reducing engine speed. With a given of engine speed, the vacuum changed gradually with throttling. While with a given position of throttling valve, the vacuum changed significantly with engine speed. Based on this result, we can design the vacuum valve to supply gas fuel for the engine.
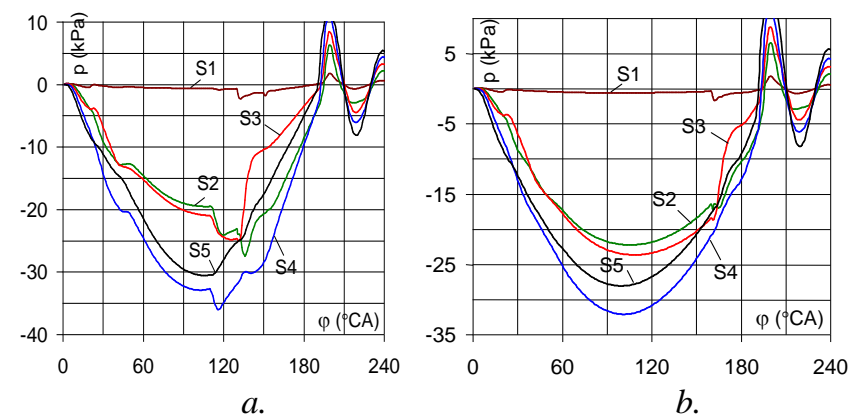

Fig. 6: Variation of static pressure on the cross sections S1, S2, S3, S4 and S5 according to crankshaft rotation angle as the throttle valve position $\alpha=0^{\circ}$

(a) and $\alpha=30^{\circ}$ (b) (n=3000 rpm, with biogas-HHO gas supply)

The vacuum pressure in the intake manifold is slightly affected as fuel injection. Fig. 6a and Fig. $6 \mathrm{~b}$ present the variation of pressure at observed cross sections when supplying biogas and $\mathrm{HHO}$ through the corresponding injectors with throttling valve at position $\alpha=0^{\circ}$ and $\alpha=30^{\circ}$. The engine operates at speed of $3000 \mathrm{rpm}$. As compared to the Fig. $3 a$ and Fig. $3 b$ it can be seen that the vacuum slightly decreases when fuel injection starts, and it increases just after fuel injection stops. This effect is more clearly as the flow section is less throttled.

\section{B. Technique of air-fuel ratio control for biogas-HHO gas engine}

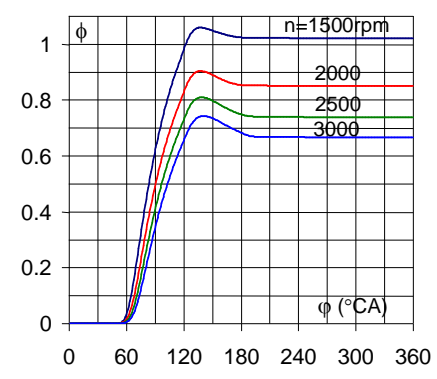

$a$.

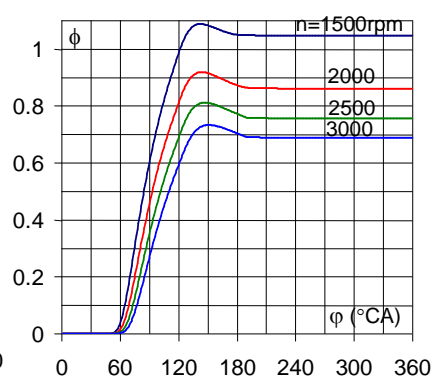

b.
Fig.7: Effects of engine speed on variation of equivalence ratio according to the crankshaft rotation angle as $\alpha=0^{\circ}$ (a) and $\alpha=45^{\circ}$ (b) (Injection of biogas $\mathrm{M} 7 \mathrm{C} 3$ and $\mathrm{HHO}$ gas)

Fig. 7a and Fig. $7 \mathrm{~b}$ present the effects of engine speed on variation of the equivalence ratio $\phi$ according to the crankshaft rotation angle of engine fueled with biogas-HHO gas in two cases of throttle valve position: $\alpha=0^{\circ}$ and $\alpha=45^{\circ}$. Under a fixed fuel supply condition, when the engine speed increases, the equivalence ratio strongly decreases. As mentioned above, when engine speed increases, the vacuum level increases, this is in favor to introducing more fuel to the cylinder. But in this case, the time (in s) for fuel supply period is reduced. Fig. 3a and Fig. 3b show that with given vacuum pressure, the crankshaft angle of the valve opening (in terms of the crankshaft rotation angle, ${ }^{\circ} \mathrm{CA}$ ) increases 
with increasing engine speed. However, the amount of gas introduced into the intake manifold depends on the time of the valve opening (in seconds). When the engine operates at high speed, at the same time interval in seconds, the crankshaft rotates a larger angle than that at low speed. It results in a reduction of fuel introduced to the cylinder. The magnitude of reducing of $\phi$ is almost independent with the butterfly valve position. Thus, the conventional gas supplying system should be modified to meet the requirements of the engine fuel with biogas-HHO gas.
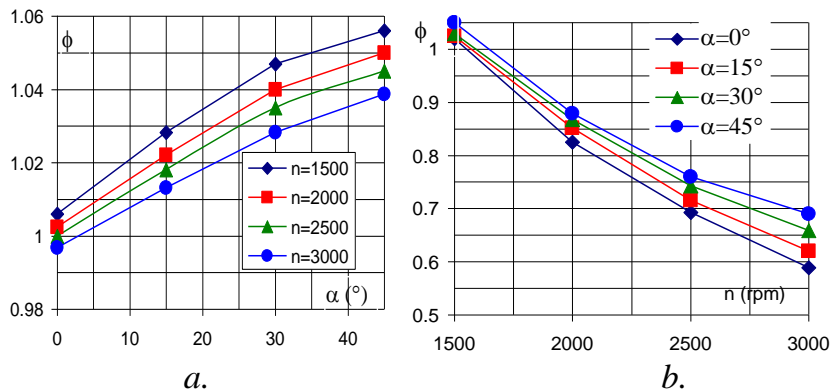

Fig. 8: Effects of engine speed on variation of $\phi$ with respect to $\alpha$ (a) and effects of butterfly valve position on variation of $\phi$ with respect to $n$ (Engine is fueled with biogas M7C7 and HHO gas by conventional gaseous fuel supply valve)

Fig. 8a and Fig. 8b present the variation of equivalence ratio as the engine is fueled by conventional gaseous fuel supplying valve. Fig. 8a shows that when the fuel injection condition is fixed for $\phi=1$ at $\alpha=0^{\circ}$ independently engine speed, the equivalence ratio changes very slightly as changing of butterfly valve position. In average, $\phi$ changes from 1 to 1.05 as $\alpha$ varied from $0^{\circ}$ to $45^{\circ}$ (Fig. 8a). But when the fuel injection condition is fixed for $\phi=1$ at $n=1500 \mathrm{rpm}$ independently throttle valve position, the equivalence ratio drops down sharply as increasing of engine speed (Fig. 8b). The equivalence ratio decreases from 1 to 0.65 as engine speed increases from $1500 \mathrm{rpm}$ to $3000 \mathrm{rpm}$ in this condition.

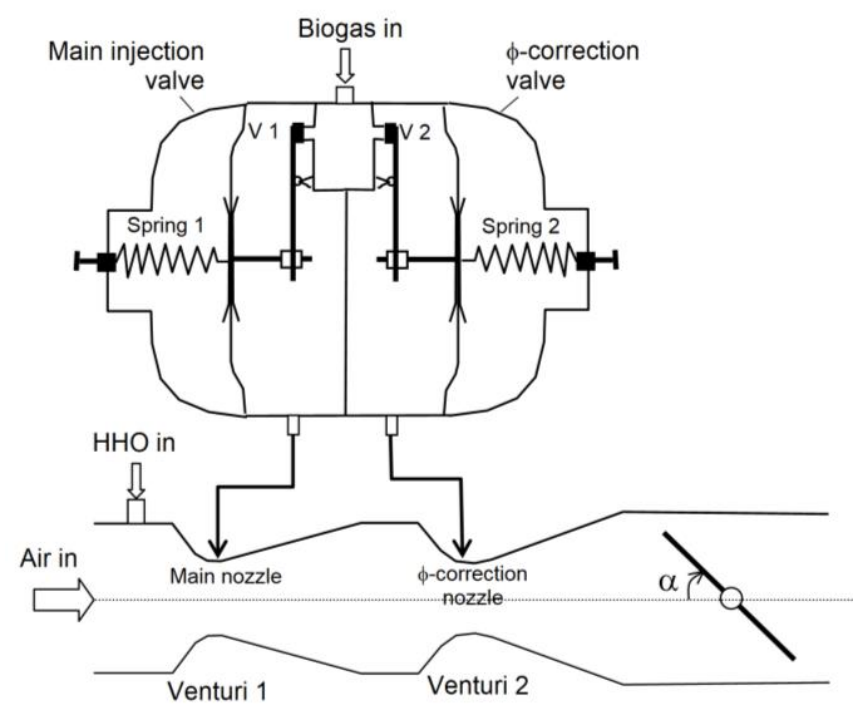

Fig. 9: Schema of biogas-HHO supplying system for SI engine

The above results show that it is not necessary to adjust the equivalence ratio according to the opening level of throttle valve, but it is important to control air-fuel ratio as varying engine speed. Due to the equivalence ratio varies strongly with engine speed in the same fuel supply condition and the same throttle opening position, if the mixture is adjusted suitably for low-speed engine operation, then at high engine speed the mixture is too poor, thus, the engine cannot operate. Conversely, is adjust the optimal mixture for high speed operation, then when the engine is operating at low speed, the mixture will be too rich, beyond the limit of combustion. So, the air-fuel ratio must be adjusted by supplying a supplement quantity of fuel as increasing of engine speed. The basic principle of the technique of biogas-HHO supply is based on the effect of engine speed on vacuum in intake manifold analyzed above.

The schema of biogas-HHO supply system is shown in Fig. 9. It is a compact gaseous fuel supplying valve with the input is connected to biogas source and the outputs are connected to the biogas injectors. The normal close van inside the compact valve in controlled by the balance between the spring tension and vacuum pressure applied on the membrane. In this schma, venturi 2 is the original one of the engine and venturi 1 is new one. The tension of the spring 1 and the spring 2 can be adjusted by the screws. As the diaphragm diameter of the compact valve has been fixed, the timing of closing, opening of the valve, i.e. the interval time of the gas supply can be adjusted through adjusting the spring tension so that the valve operates within the desired vacuum range.

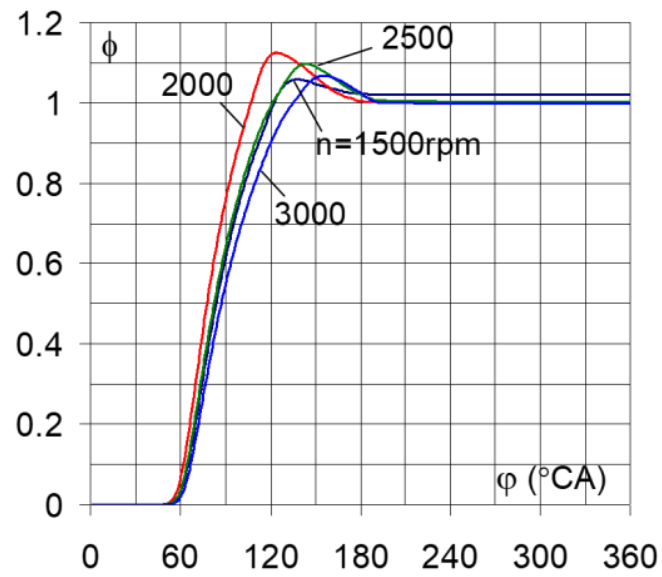

Fig 10: Effect of $\phi$-correction valve on the variation of equivalence ratio with respect to $\varphi$ as the engine fueled with biogas-HHO operates at different speeds

Fig. 10 shows the variation of equivalence ratio $\phi$ when the engine operates at full load regime with different engine speeds fuel with biogas enriched by HHO through the compact valve. The injection time of biogas is variable according to the vacuum at the cross section S2 and S4. The injection time of $\mathrm{HHO}$ is fixed. Valve 2 is closed at low speed and it is opened gradually as increasing of engine speed due to increasing of vacuum pressure. It can be observed that when the $\phi$-correction valve is added, the equivalence ratio can be adjusted around $\phi=1$ under different engine speeds. Besides the adjustment of equivalence ratio by the $\phi$ correction valve, the presence of HHO gas in fuel mixture improves combustion properties, allows an extension of 
combustion limit. This helps to recover the stability of the engine as speed changes suddenly.

Fig. 11a presents contour of $\mathrm{CH}_{4}, \mathrm{H}_{2}$ concentrations and $\phi$ at $90^{\circ} \mathrm{CA}$ and $180^{\circ} \mathrm{CA}$ as supplying biogas and $\mathrm{HHO}$ by the compact valve. At $90^{\circ} \mathrm{CA}$, the three injectors operate but the biogas contributes the majority portion of $\phi$. At $180^{\circ} \mathrm{CA}$, the injectors closed, the fuels are mostly introduced into the cylinder. At closing of intake valve, some proportion of fuels still remain in the intake manifold.

Fig. 11b shows that at the end of the compression process, the equivalence ratio in the combustion chamber varies from 0.85 to 1.02. The poor mixture region is found around intake port and the rich mixture is in the opposite side. The equivalence ratio is around 0.97 in the region of spark plug.

Fig. 12 presents the structure of the compact valve and its installation on the Samdi S3600B-1 engine. Biogas from the digestor is supplied to the valve after passed the $\mathrm{H}_{2} \mathrm{~S}$ removal. $\mathrm{HHO}$ produced by the electrolyze powered by solar panels is introduced directly to the mixer. The gasoline supply system of the engine is unchanged; thus, the engine can operate with petrol in case of necessary as before conversion. The system has been tested and approved the efficiency under different operating conditions in the practice.

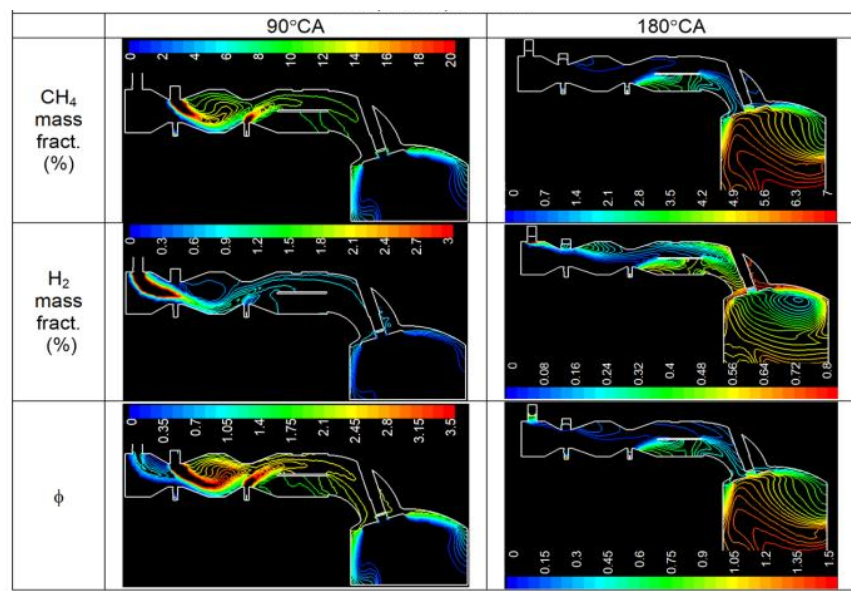

a.

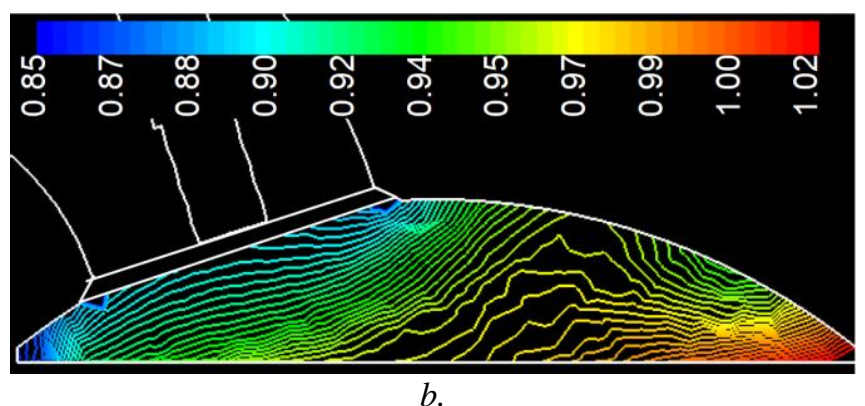

Fig. 11: Distribution of fuel compositions and equivalence ratio as fuel supplying by compact valve. (a) Contour of $\mathrm{CH}_{4}, \mathrm{H}_{2}$ concentrations and $\phi$ at $\varphi=90^{\circ} \mathrm{CA}$ and $\varphi=180^{\circ} \mathrm{CA}$; (b) Contour of $\phi$ at the end of compression process

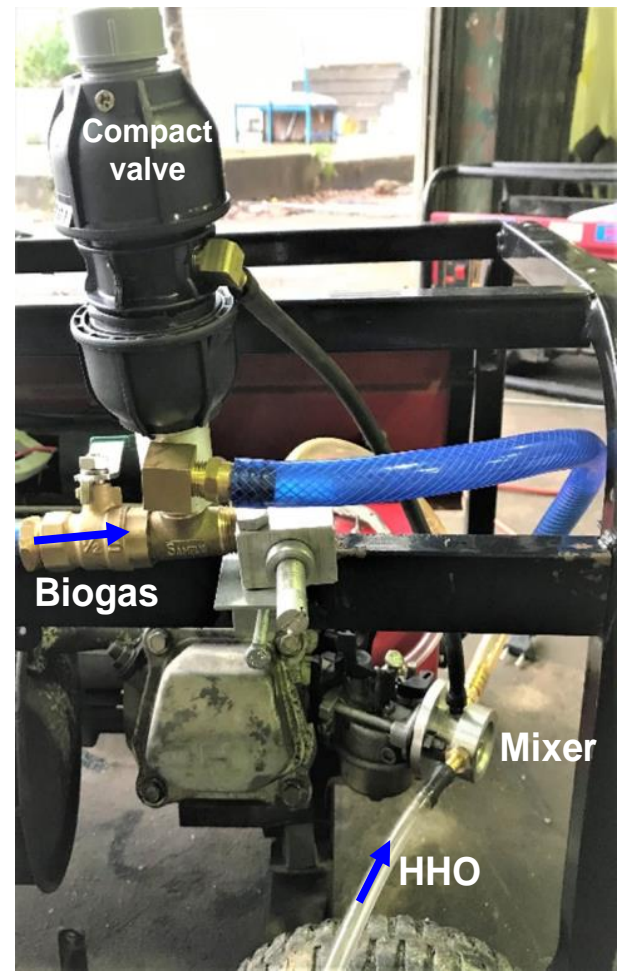

Fig. 12: Biogas-HHO supplying system for the Samdi S3600B-1 engine

\section{CONCLUSION}

Based on the above analysis, the following conclusions can be drawn:

- The maximum vacuum at the downstream venturi is about $10 \mathrm{kPa}$ higher than that at the upstream venturi. Vacuum at the venturi throat increases significantly with engine speed and the peak of the vacuum curve tends to shift toward the end of the intake process as increasing of engine speed.

- The vacuum at the throttle venturis decreases as decreasing of engine speed or/and increasing of flow obturation. The tendency of variation of vacuum pressure at the upstream venturi and at the downstream venturi not quite different but the absolute value of vacuum in the second case is about $40 \%$ higher than that of the first case.

With the conventional gaseous fuel supplying system, the equivalence ratio $\phi$ of biogas-HHO fueling engine decreases significantly as increasing of engine speed. With the same gas supply condition, the suitable mixture for low engine speed becomes too poor at high engine speed; conversely, optimal mixture for high engine speed becomes too rich at low engine speed.

A supplement fuel supplying valve is needed to correct the equivalence ratio of the engine fueled with biogas-HHO. The valve operates under effect of vacuum at the downstream venturi to supply a 
compensation quantity of fuel as increasing of engine speed.

- The compact kit composed by a mixer, a compact biogas valve (included main injection valve and $\phi$ correction valve), providing a stable equivalence ratio around stoichiometric value, demonstrated appropriate technique for biogas-HHO supplying to SI engine in practice.

\section{ACKNOWLEDGMENT}

The authors wish to express their appreciation to the Ministry of Education and Training for supporting this research project as part of the Ministerial Program of Science and Technology CTB.2018.DNA "Research Development of a hybrid renewable energy system biogas-solar for rural areas in Vietnam"

\section{REFERENCES}

[1] Kumar, M. \& Shen, T.: Estimation and feedback control of air fuel ratio for gasoline engines. Control Theory and Technology. May 2015, Volume 13, Issue 2, pp 151-159, https://doi.org/10.1007/s11768-015-4148-9.

[2] Danardono, D., Kim, KS., Lee, SY. et al.: Optimization the design of venturi gas mixer for syngas engine using three-dimensional CFD modeling. J Mech Sci Technol (2011) 25: 2285. https://doi.org/10.1007/s12206-011-0612-8

[3] GUIBET Jean-Claude: Carburants et moteurs. Editions Technip, 1997

[4] Patent No. 6643 "Functional three-valve system supplying gas fuel for LPG/gasoline motorcycles". Intellectual Property Department, 09-10-2007

[5] Pengwei Li; Jing Wang; Wenyuan Cai: Intelligent control for airfuel ratio of compressed natural gas engine. 2013 Fourth International Conference on Intelligent Control and Information Processing (ICICIP) DOI: 10.1109/ICICIP.2013.6568160

[6] Turin, R. and Geering H.: Model-Reference Adaptive A/F Ratio Control in an SI Engine Based on Kalman-Filtering Techniques. American Control Conference, 1995, pp. 4082 - 4090

[7] Powell, J. D., Fekete, N. P., Chang C. F.: Observer-Based AirFuel Ratio Control. IEEE Control Systems Magazine, vol. 18 , issue 5, pp. 72-83, Oct 1998.

[8] Mianzo, L., Peng, H., Haskara I.: Transient Air-Fuel ratio Ho Preview Control of a Drive-by-Wire Internal Combustion Engine. American Control Conference, 2001, pp. 2867 - 2871

[9] Muske, K. R., Jones, C. P. J.: A Model-based SI Engine Air Fuel Ratio Controller. American Control Conference, 2006, pp. 3284 3289

[10] Chang, C. F., Fekete N. P., Powell J. D.: Engine Air-Fuel Ratio Control Using an Event-Based Observer. SAE Paper No. 930766, 1993

[11] Bui Van Ga, Tran Van Nam, Nguyen Thi Thanh Xuan: Utilization of biogas engines in rural area: A contribution to climate change mitigation. Colloque International RUNSUD 2010, pp. 19-31, Universite Nice-Sophia Antipolis, France, 23-25 Mars 2010

[12] Bui Van Ga, Nguyen Van Đong, Nguyen Van Anh, Truong Le Bich Tram: Study on the system of supplying compressed biogas for motorcycles. Transportation Journal, No 12/2009, pp. 79-82, 2009

[13] Bui Van Ga, Tran Van Nam, Bui Thi Minh Tu, Nguyen Quang Trung: Numerical simulation studies on performance, soot and NOx emissions of dual-fuel engine fuelled with hydrogen enriched biogas mixtures. IET Renewable Power Generation: Volume 12, Issue 10, (2018), pp. 1111-1118, DOI: 10.1049/ietrpg.2017.0559

[14] Bui Van Ga; Phan Minh Đuc; Nguyen Van Đong: Predicting the distribution of temperature and NOx in the combustion chamber of the spark ignition engine powered by biogas enriched by hydrogen. Journal of Science and Technology-Danang University, Vol. 1, No. 11(32), 2018
[15] Bui Van Ga, Nguyen Viet Hai, Nguyen Hoang Nguyen: Calculation of valves supplying biogas-air mixture for selfigniting motor by compression with FLUENT software. Journal of Science and Technology-Danang University, No.4(39)/2010, pp 88-95

[16] Bui Van Ga, Tran Thanh Hai Tung: Constructing the characteristic road of the mixture generator of the forced ignition engine using compressed biogas. Transportation Journal, No. 11/2010, pp. 35-37

[17] Bui Van Ga, Tran Van Nam, Le Xuan Thach: Flow simulation through a mixture of spark ignition biogas engine with Fluent software. Journal of Science and Technology of Technical Universities, No. 80-2011, pp. 134-138

[18] Bui Van Ga, Tran Thanh Hai Tung, Tran Van Nam, Le Xuan Thach: Simulation of flow through biogas supply unit for gasoline-biogas engine GATEC-21. National Conference of Water Mechanics, Cualo, July 21-23,2011, pp.125-130

[19] Tran Thanh Hai Tung, Bui Van Ga, Duong Viet Dung, Nguyen Huu Huong: Simulation of flow in the supply of biogas for biogasdiesel engines GATEC-20. National Conference of Water Mechanics, Cualo, July 21-23,2011, pp.661-668

[20] Bui Van Ga, Tran Van Nam: Mixer Design for High Performance Biogas SI Engine Converted from A Diesel Engine. International Journal of Engineering Research \& Technology (IJERT, http://www.ijert.org), Vol. 3 Issue 1, January - 2014, pp. $2743-$ 2760

[21] Patent No. 9562 "Biogas fuel supply system for stationary engines runs on two biogas-gasoline fuels". Intellectual Property Department, 16-08-2011

[22] Bui Van Ga, Bui Thi Minh Tu, Truong Le Bich Tram, Vo Nhu Tung, Do Xuan Huy: Combustion improvement of engine fueled with poor biogas by blending hydroxyl (HHO). Journal of Science and Technology-The University of Danang, Vol. 17, No. 1.1, 2019 , pp. 35-41 